\title{
The Capacity of Groups within the Community to Carry out Plant Pest Surveillance Detection
}

\author{
Peter Mangano ${ }^{1}$, Darryl Hardie*, ${ }^{*}$, Jane Speijers ${ }^{1}$, Richard Johnston ${ }^{1}$, Maria J. de Sousa-Majer ${ }^{1,3}$ and \\ Glynn Maynard ${ }^{2}$
}

${ }^{I}$ Department of Agriculture and Food, Western Australia, 3 Baron-Hay Court, South Perth, WA 6151, Australia; ${ }^{2}$ Office of the Chief Plant Protection Officer, Department of Agriculture, Fisheries and Forestry, GPO Box 858, Canberra, ACT 2601, Australia; ${ }^{3}$ CRC for National Plant Biosecurity, GPO Box 5012, Bruce, ACT 2617, Australia

\begin{abstract}
A set of trial exercises was run to compare pest surveillance capabilities of the Department of Agriculture and Food's entomology and plant pathology staff (all with some degree of field survey experience) with persons from various community groups. Information indicating a comparable level of confidence in the use of community members for surveillance, to complement professional staff capacity, is provided.
\end{abstract}

Keywords: Community surveillance, International Plant Protection Convention, plant pest, SPS agreement, surveillance.

\section{INTRODUCTION}

In Australia, as elsewhere in the world, the number of experienced surveillance personnel is limited and decreasing [1]. Also, dealing with pest incursions is a challenging task that requires effective planning and resourcing [2]. When designing a surveillance program, the difficulty lies in deciding and prioritizing on how, where, when and what to look for, as elegantly explained by Hellström [3] and mentioned by Steven [4] in the foreword of 'Surveillance for biosecurity: Pre-border to pest management'. Regular surveys can be very time consuming and costly to perform [5-7]. The cost of rapid assessment surveys in USA was US\$ 60,000 to 250,000 per survey and in Australia, port baseline surveys using Hewitt and Martin protocols [8] cost on average US\$ 96,000 per survey. Some exotic pest incursions in Australia have warranted a nationally coordinated and funded response, with combined expenditure exceeding AU\$200 million [2].

The personnel and financial resources of the agencies responsible are usually fully committed, such that there is no capacity to readily undertake new or emergency surveillance work. Consequently, in recent years there has been recognition of the need for development of community-based surveillance [9]. Community-based surveys provide a means of addressing ISPM 04 requirements to survey for Area Freedom. They also have the additional benefit of increasing general community awareness of important exotic diseases, pests and weeds and increasing the likelihood of early detection, containment and/or eradication $[9,10]$. For successful surveillance programs, early detection of a pest and a rapid control response are crucial for a successful outcome $[3,6]$.

\footnotetext{
*Address correspondence to this author at the Entomology Branch, Department of Agriculture and Food Western Australia, 3 Baron-Hay Court, South Perth, WA 6151, Australia; Tel: +61 (0)8 9368 3799; Fax: +61 (0)8 9368 3223; E-mail: dhardie@agric.wa.gov.au
}

In Australia, the Department of Agriculture, Fisheries and Forestry (DAFF) is the organization that delivers the Australian Government's plant health role through its Biosecurity Services Group. According to Pheloung [2], the Australian government is responsible for managing risks at national borders and coordinating the response to new pest incursions. States and Territories, individually or together, work to resolve the problem within the Country. In Western Australia, the Department of Agriculture and Food (DAFWA) is the organization that manages investment in agricultural biosecurity services [11].

In addition, as a contracting party to the International Plant Protection Convention (IPPC), Australia needs to confirm the absence of pests, rather than consider a pest absent due to lack of reports. Similarly, it would be useful to have some understanding of the degree of reliability of community groups as a resource for surveillance. Furthermore passive surveillance has a greater advantage over active surveillance programs because they are only justifiable when the cost of a potential incursion, and its successful eradication, is dependant on a short time period between initial incursion and identification [12]. The control or eradication cost for a new invasive species is becoming an economic burden in many countries, for example in New Zealand where it is estimated to be around 1\% of GDP $[9,13]$.

Our knowledge is currently deficient on how invasive species may impact upon our ecosystems. There is a need to demonstrate that a target pest (invertebrate, plant disease or weed) is "known not to occur" through active surveillance, rather than assuming that because the organism has not been detected in passive (or other casual) surveillance, it is absent (not known to occur) [14]. This information has become crucial for the maintenance of interstate and international agricultural and horticultural markets $[2,15,16]$. If a country wishes to trade with other countries, there is often a necessity to be able to declare 'Area Freedom' from certain diseases, pests or weeds that are associated with imports or exports $[14,17]$. The guidelines of International Standards for 

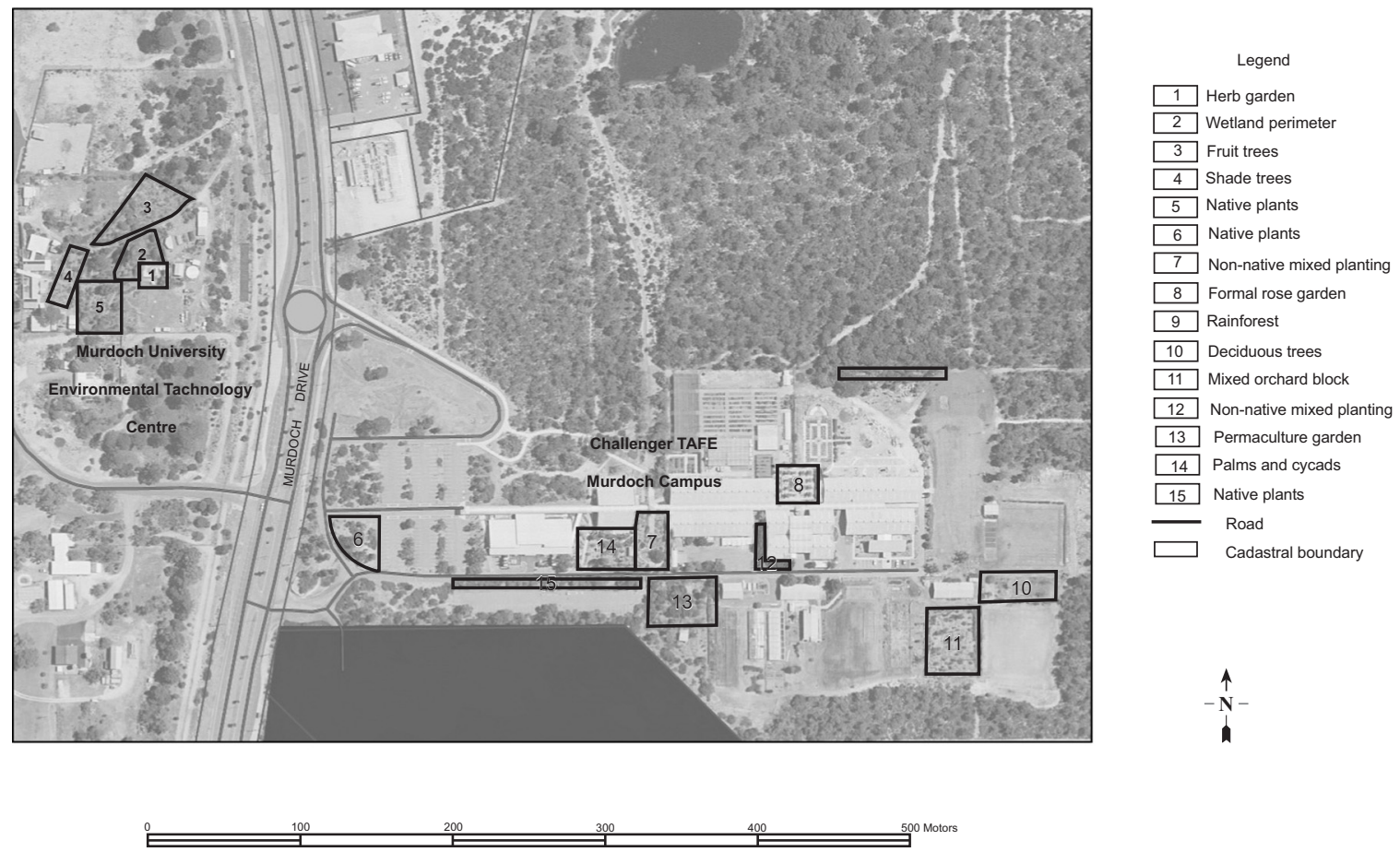

Fig. (1). Aerial map of the site (Western Australia Horticulture and Environmental Science Skills Centre of Challenger TAFE and the Environmental Technology Centre of Murdoch University, Perth, Western Australia), showing zones used in the surveillance exercise.

Phytosanitary Measures [18] of the IPPC require the exporting country to provide a scientific account of 'Area Freedom'. This usually entails surveying a given region and/or host crop on a regular basis $[14,16,18,19]$ to ensure freedom from certain pests.

Australia and New Zealand are increasingly relying on a passive surveillance program that involves the general public, industry, biosecurity service and science community to notify the responsible organization of any suspected invasive pest or disease (e.g. pest emergence hotline) [20]. The purpose of this paper is to address the relationship between pest incursions and surveillance programs involving community groups. In the event of an incursion of a plant pest ${ }^{1}$ into Australia, there is a need to rapidly deploy people to discover the extent of the pest incursion. To this end, it would be useful to understand the general capability of particular groups within the community and their potential, if deployed during an emergency, to detect the target pest.

This study was designed to compare the capabilities of non-professional community members with professionals in surveillance programs. To enhance the success of future pest surveillance activities, a surveillance exercise was carried out to assist with: 1) the choice of surveillance personnel; 2) the design of future surveillance activities; 3 ) the level and type of surveillance activities; and 4) the level of confidence in the results obtained from a surveillance activity.

\section{MATERIAL AND METHODS}

The surveillance exercise drew on community groups who might be available for surveillance activities. Comparison of the results of community members to that of profes-

${ }^{1}$ Pest "Any species, strain or biotype of plant, animal or pathogenic agent injurious to plants or plant products" ISPM 5 Glossary of Phytosanitary terms. sional entomologists, plant pathologists and other technical staff from the DAFWA (who although highly skilled in their area of expertise, were not necessarily highly skilled in surveillance for the particular target pests) for the detection of novel non-factual pests was made to establish the effectiveness of these groups. The experiment was carried out in Perth, Western Australia at the Horticulture and Environmental Science Skills Centre of the Challenger Technical and Further Education Institute (TAFE), and at Murdoch University's Environmental Technology Centre.

\section{Study Zones}

Fifteen discreet zones were used, each with a unique habitat type. Zones varied considerably in terms of habitat and size (Table 1), as well as shape (Fig. 1).

\section{Procedures for Personnel Recruitment}

The participants (excluding DAFWA staff) were respondents to a one-off advertisement placed in a community newspaper and brochures displayed at Challenger TAFE and Murdoch University (Fig. 2). The participants were randomly selected from over 700 applicants and paid an honorarium of $\$ 80$ upon completion of the exercise. Payment was provided to ensure unbiased attendance by the participants on the day of the exercise and to ensure completion of the task. In an actual surveillance exercise, surveillance personnel would be paid, so the honorarium mimicked a real life situation.

\section{Descriptions of Personnel}

There were 126 people selected to undertake the surveillance exercise. These were from three community groups (108) and the DAFWA professional group (18) - control group. The groups were: Group I- full time students who 
Table 1. Description and Sizes of each Zone

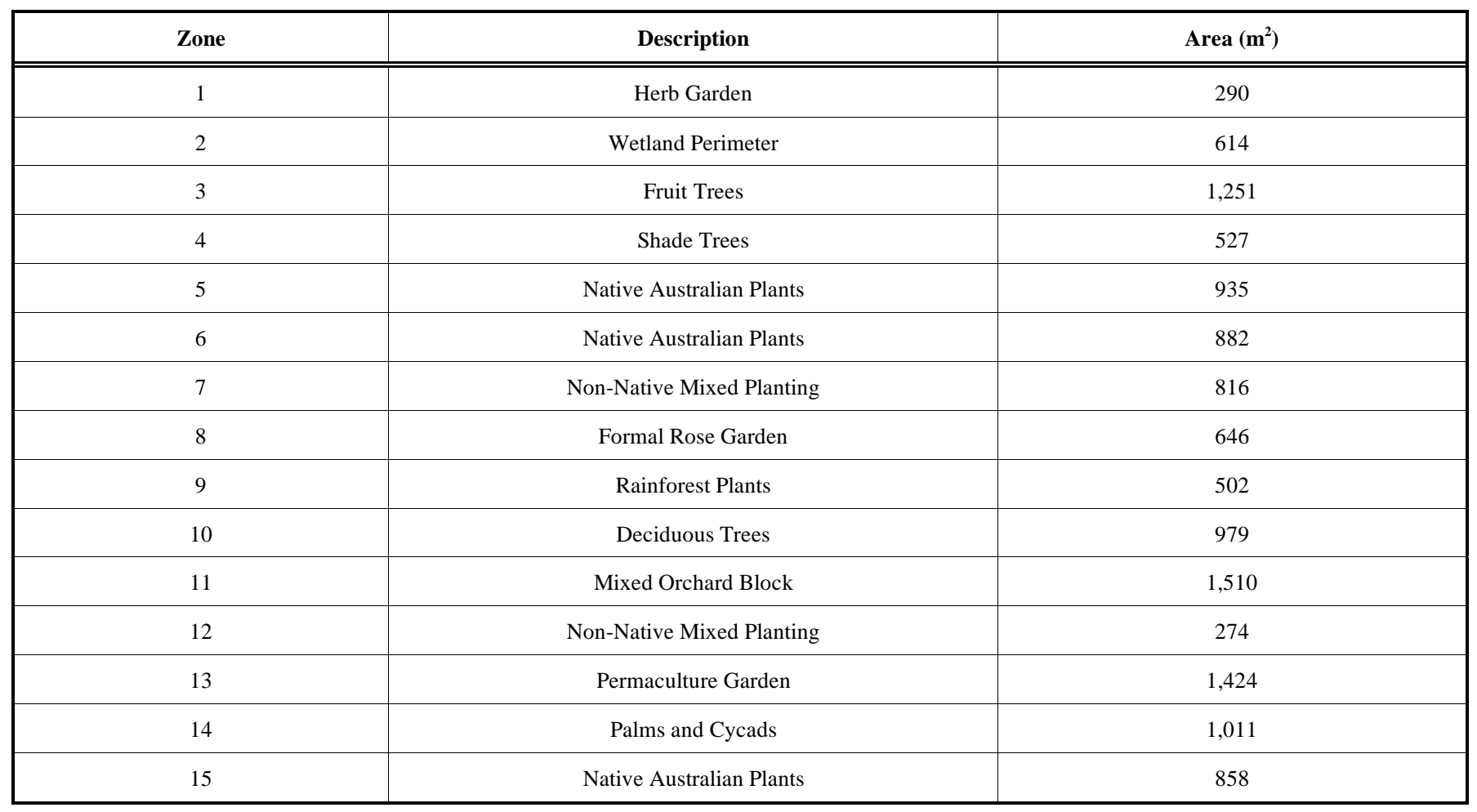

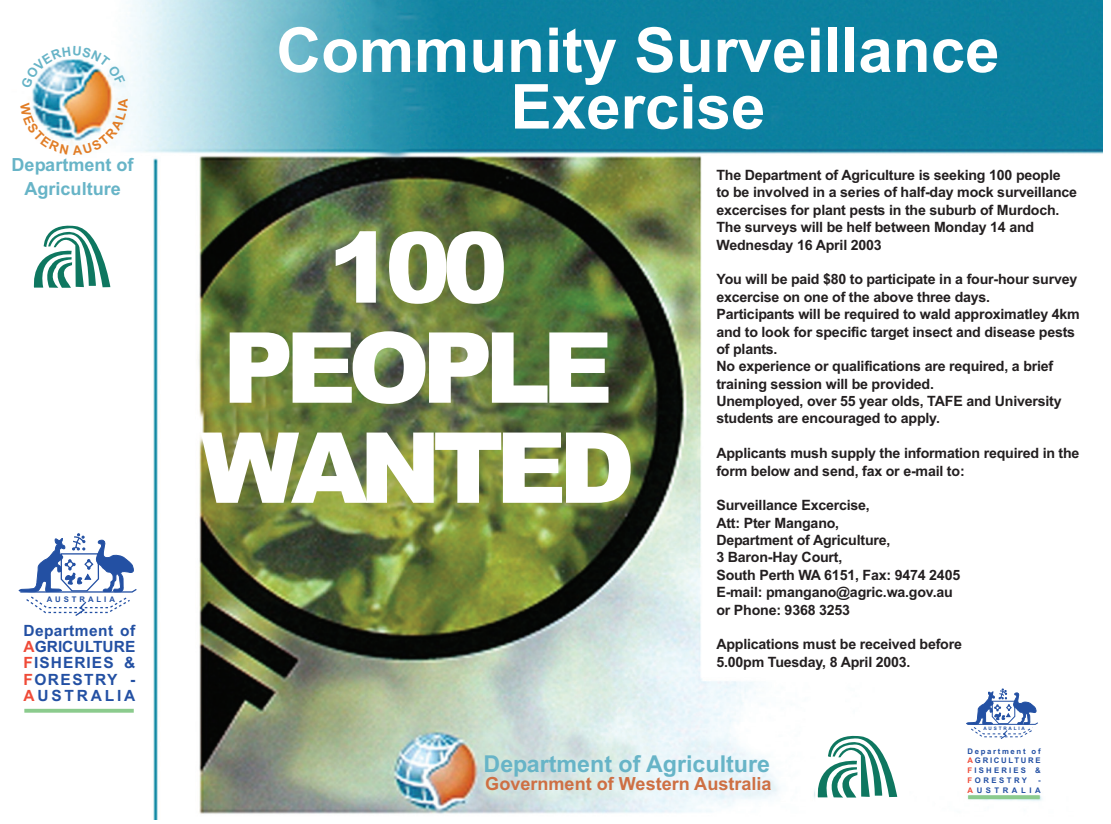

Fig. (2). Advertisement to attract participants for the surveillance exercises using a fictional pests.

were undertaking university or other post-secondary school studies; Group II- long term unemployed or part-time/casual employees; Group III- seniors or retirees over 55 years of age; and Group IV- DAFWA researchers or techni$\mathrm{cal} /$ professional staff with at least some experience in surveillance. The age of participants in the over 55 group ranged from 55 to 74 years, with a median age of 62 years (Fig. 3). Students ranged in age from 17 to 52 years, with a median of 22 years. The unemployed group ranged in age from 17 to 54 years, with a median of 39 years and the pro- fessional group from DAFWA ranged in age from 22 to 74 years, with a median of 44 years.

Each of the three community groups consisted of 36 individuals, comprising equal numbers of: Experienced: (nine males and nine females) and Non-experienced: (nine males and nine females). The division of participants into experienced and non experienced categories was based on their level of training and work, or life experience in biology, horticulture or agriculture. The age of each participant was recorded. Three different individuals from each group of nine 


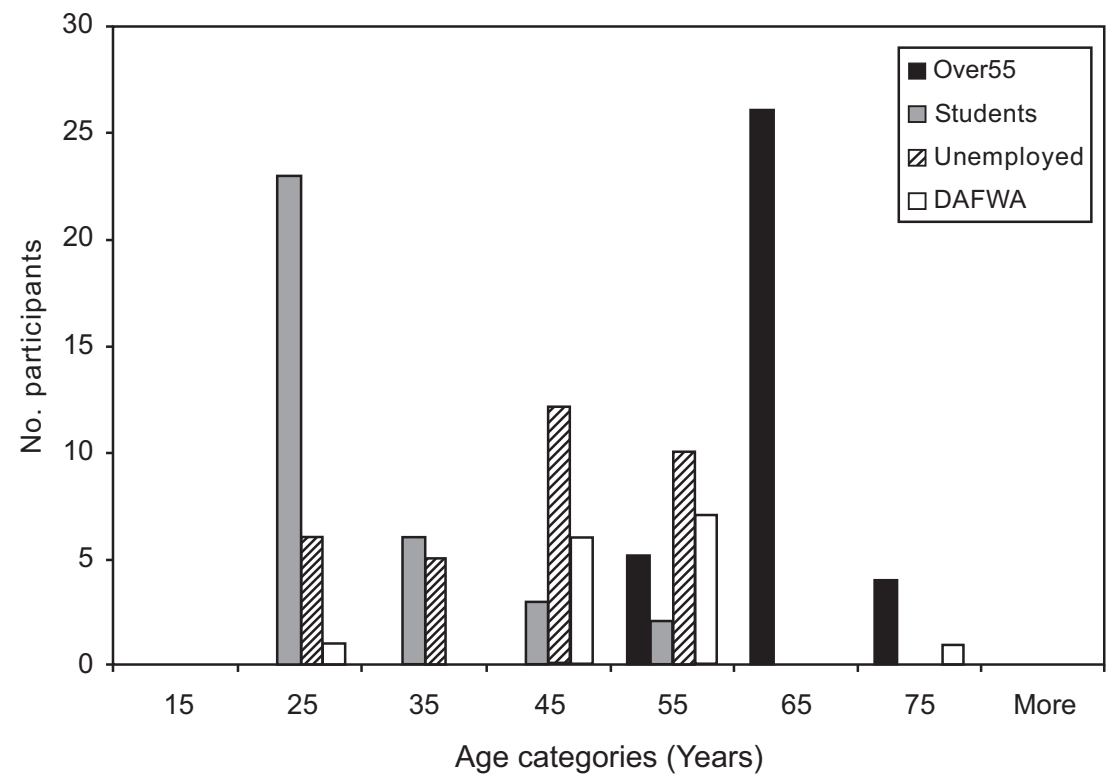

Fig. (3). Age distribution for each community group and the professional group from DAFWA.

were selected on three separate occasions (this exercise was repeated over three days). Eighteen completed the surveillance exercise in the morning and the rest in the afternoon (i.e. 36 participants per day). The DAFWA group comprised 18 people, 12 males and 6 females, which conducted the exercise on a separate day.

Each participant was asked to find fictional pests under controlled conditions. Before commencing the surveillance exercise, participants were given a 45 minute briefing on how to undertake the surveillance and detailed information on the appearance and biology of the fictitious target pests. They were also provided with coloured images of the fictitious pests that they could refer to whilst undertaking the exercise.

\section{Surveillance Targets}

For this study, fictitious pest organism symptoms were used that had a resemblance to real organisms or actual plant damage. Fictitious pests, were used so that there was consistency in the position and appearance of the organisms over the three days of the exercise. It also provided no advantage to any of the individuals undertaking the exercise by them having prior experience of the organisms.

\section{Pest Description}

The fictitious pests were the 'toxic blue snail'; the 'cryptic leaf cutter beetle' and 'aggressive pink rust' (Fig. 4). In the case of the toxic blue snail, conical marine snails were sprayed with pale blue paint (Australian Export Gloss

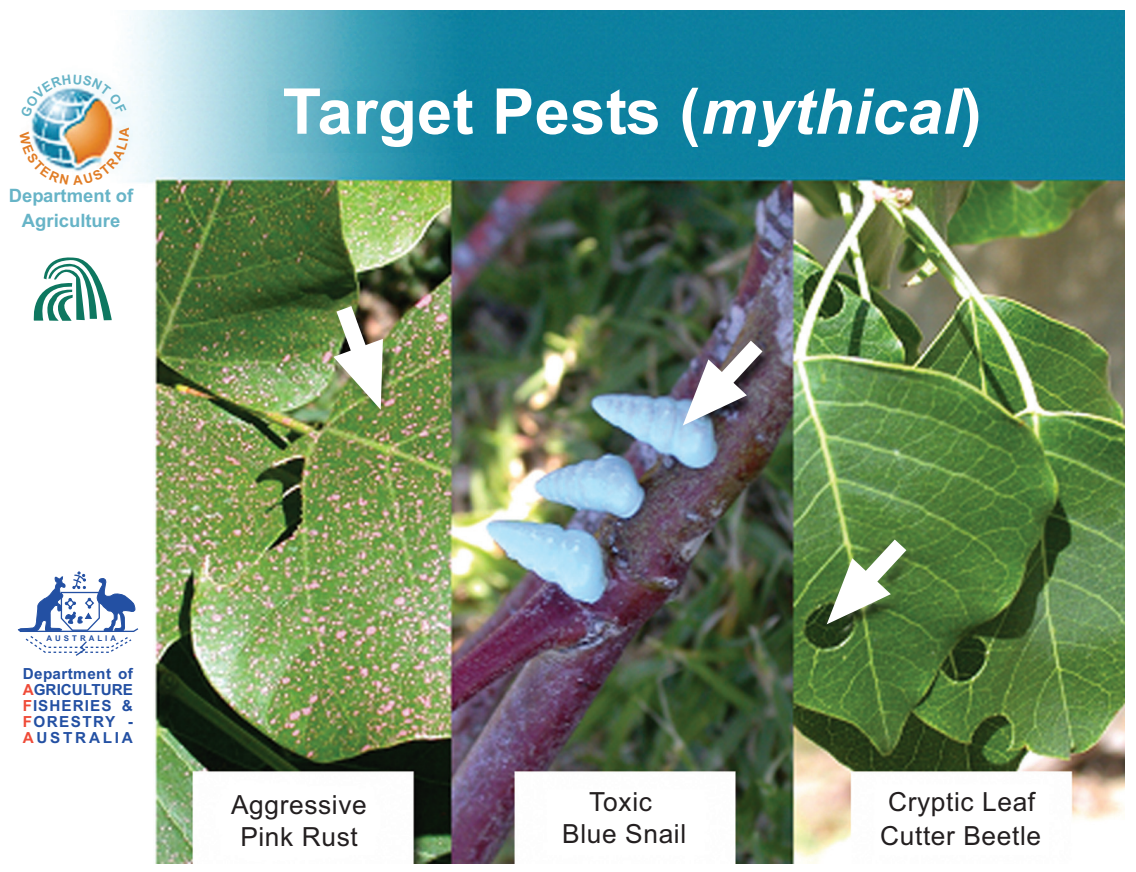

Fig. (4). Images of the fictitious pests used in the surveillance exercise. Arrows on the pictures above indicate the target pest. 
Enamel $^{\circledR}$-Creation Blue) and glued to selected trees in three of the 15 zones in clusters of seven snails per tree.

The snails were placed in crevices or at limb junctures 1.5 metres above ground level in three zones. For 'damage' caused by the cryptic leaf cutter beetle, a paper hole-punch was used to create small round holes (diameter $5 \mathrm{~mm}$ ) in leaves (holes).

This target was placed at six of the 15 zones in densities of 16 holes in a cluster of leaves on a tree or shrub. For aggressive pink rust, a coarse spray of hot pink acrylic paint (British Paints, colour-Mexican Chilli) was applied to most of the leaves on selected trees or shrubs to give the appearance of rust pustules. A single plant was sprayed at three of the 15 sites.

Target pests were placed in 12 of the zones and three of the zones had no target pests. The participants were informed that each zone contained at maximum of one pest type and were given 10 minutes alone in each zone to search for the hypothetical pest. Results were recorded as 'not found', 'correctly found' or 'incorrectly found' (i.e. false positive).

\section{Statistical Analysis}

A linear mixed model was used to examine the effects of day, time of day (AM versus PM), profession (DAFWA versus community participants), age, experience (yes or no), gender, community category (over 55, student, unemployed), pest and their interactions on: 1) the probability of finding the correct pest (for the 12 zones with pests the response was either correct or incorrect); and 2) the probability of false positives (for all 15 zones the response was either false positive when the incorrect pest was found or not false positive when the correct pest was found or no pest was found). In this model, the effects of individual and zone were fitted as random effects and all other effects were fixed. Estimates of the effects of significant factors and variates (age) were made using a model which excluded non-significant interactions.

\section{RESULTS AND DISCUSSION}

Individuals from each of the three community groups completed the exercise. Six selected individuals failed to show up for the exercise ( 3 in the unemployed group, 2 in the student group and 1 from the over 55's). The DAFWA group undertook the exercise on a separate day prior to the main test groups. This was unfortunate but unavoidable, because the researchers were needed to test the system. We can not rule out a day effect for these participants, but we think that it is unlikely.

Our preliminary setting-up of the surveillance indicated that test participants needed clear and concise briefing information prior to the exercise and many had difficulties following basic maps, needed guidance around the surveillance circuit and had trouble disciplining themselves to the required time limit per zone. These issues were addressed before the actual exercise when Departmental staff acted as impartial marshals and timekeepers to maintain consistency between participants. The DAFWA group were tested in the absence of these additional supervision improvements.

The time constraint (10 minutes) within each surveillance zone area $\left(274-1,510 \mathrm{~m}^{2}\right)$ influenced the surveillance out- come and is a useful benchmark for future operations or research. The requirement for participants to look for three target pests is likely to have led to poorer performance than had they been required to look for only one pest. Most surveillance operations involve hours, days or even weeks of visual inspections by staff, without necessarily finding any target pests. This can lead to feelings of hopelessness and lack of enthusiasm. Contrastingly, this surveillance exercise had several zones where most participants were rewarded by finding a target pest, leading to increased motivation.

Public understanding of the anticipated economic and ecological impacts of response actions (to a pest incursion), as well as the benefits associated with this response efforts (to eradicate the introduced pests), is important to success [10]. Interviews and discussion with some participants revealed that many of them were aware of the importance of protecting and maintaining Australia's bio-diversity by excluding exotic pest species. Some commented that they would be willing to offer their services for future surveillance activities without any financial reward. This attitude could be channelled into voluntary community surveillance activities if there was a simple provision of biosecurity information, group presentations and other technical support.

\section{Probability of Finding the Correct Pest}

The number of targets detected by individual participants ranged from 0 to 10 , with a mean score of 4.0 out of a possible 12. There was a significant difference in age between the community groups, with students having a mean age of 25.8 year, unemployed participants having a mean age of 38.0 years and over 55's having an mean age of 61.4 years. The probability of finding the correct pest was significantly affected by experience $(\mathrm{P}=0.001)$, pest $(\mathrm{P}<0.001)$, and community group $(\mathrm{P}<0.001)$. If community group was ignored the effect of age was highly significant $(\mathrm{P}<0.001)$ and the effect of community group after removing the effect of age was not significant $(\mathrm{P}=0.410)$. There was no effect of profession. An interaction between gender and pest was barely significant $(\mathrm{P}=0.038)$, and has been disregarded since there was no other gender effect. After removing the fixed effects, there were still significant differences between individuals and zones $(\mathrm{P}<0.001)$. The linear effect of age when community groups were ignored indicated that, for every increase in age of 10 years, the probability of finding the correct pest is reduced on average by 0.029 (2.9\%) (Fig. 5). This effect was the same for all pests $(\mathrm{P}=0.209)$ and unchanged by the person's experience $(\mathrm{P}=0.246)$.

After adjusting for experience but not age, students found the correct pest significantly more often than the over 55 's ( $42 \%$ vs $29 \%$, respectively), but there were no other significant differences between community groups (DAFWA staff 37\%; Unemployed: $33 \%$ ). On average, experienced persons found the correct pest $40 \%$ of the time, whereas an inexperienced person found the correct pest only $31 \%$ of the time (Fig. 6). This difference between experienced and inexperienced personnel was the same for all pests $(\mathrm{P}=0.968)$. The detection of the correct pest also depended on the pest type. On average, snails and holes were found correctly $23 \%$ and $24 \%$ of the time, respectively, while rust was found correctly $59 \%$ of the time (Fig. 6). 


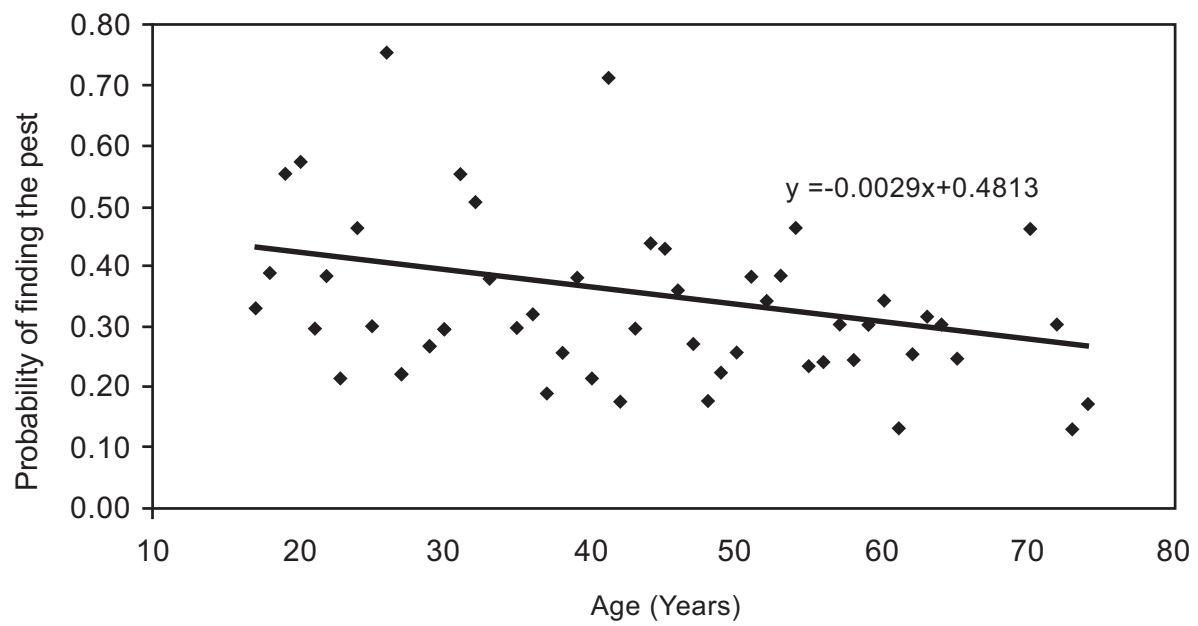

Fig. (5). Fitted linear relationship between age of participant and probability of finding the correct pest. Each point is the average for all participants of the same age after removing effects of experience.

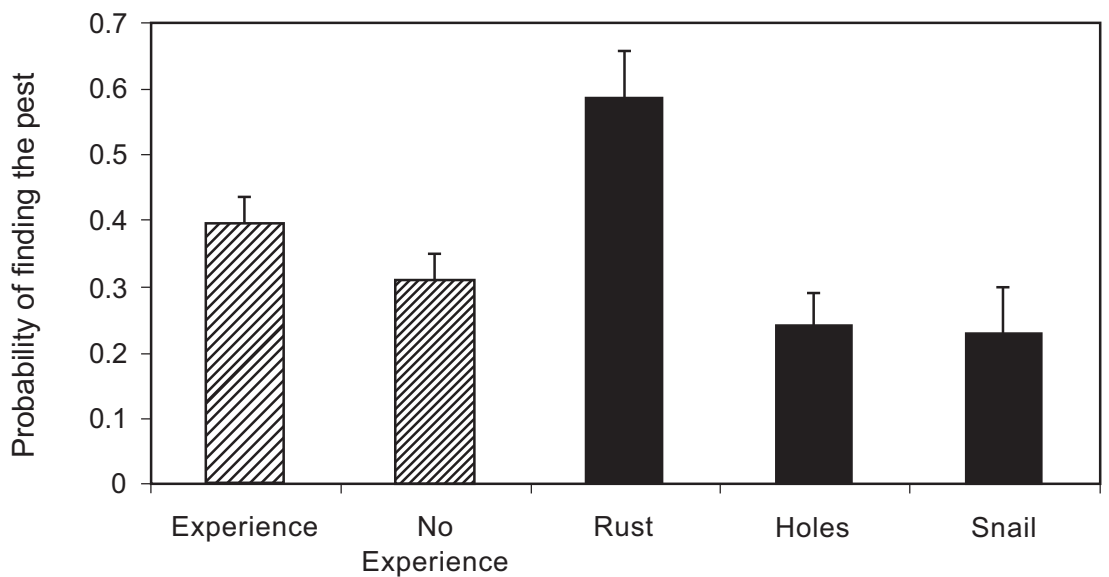

Fig. (6). Probability (+SE) of experienced and inexperienced persons finding the correct pests (shaded bars) and probability of finding the correct pest type, which are rust, holes and snails (black bars).

The largest effect was that of the individual. Of the 24 participants who found $50 \%$ or more of the pests, five were inexperienced students or unemployed, with an age range from 19 to 45 years, and the remainder were experienced participants from all categories, with an age range from 20 to 70 years.

\section{Probability of False Positives}

The number of false positives detected ranged from 0 to 15 , with an average of 2.6 per person. The probability of false positives was significantly affected by experience, by pest interaction $(\mathrm{P}=0.006)$ and community category $(\mathrm{P}=0.004)$. The effect of age after removing the effect of community group was not significant $(\mathrm{P}=0.965)$. However, the effect of age ignoring community group was significant $(\mathrm{P}=0.006)$ and the effect of community group after removing the effect of age was not significant $(\mathrm{P}=0.222)$. There was no effect of profession. After removing the fixed effects, there were still significant differences between individuals and zones $(\mathrm{P}<0.001)$.

The linear effect of age when community groups were ignored indicated that, for every increase in age of 10 years, the probability of a false positive increased on average by $0.026(2.6 \%)$ (Fig. 7). This effect was the same for all pests $(\mathrm{P}=0.368)$ and unchanged by the person's experience
$(\mathrm{P}=0.155)$. After adjusting for experience but not age, the rate of false positives was highest for the over 55 category $(25.3 \%)$, followed by the unemployed $(17.4 \%)$ and the professional (18.8\%) categories (Fig. 8). Students had only $12.2 \%$ false positives. Only the difference between the over 55 category and students was significant $(\mathrm{P}<0.05)$. Inexperienced personnel had significantly higher false positives than experienced personnel did for all pests, but the difference was greatest for snails $(\mathrm{P}<0.05)$, less for holes and when no pest was present, and very small for rust (Fig. 9). As with the probability of finding the correct pest, the largest effect was that of the individual. Of 32 participants with no false positives, three were DAFWA staff, five were over 55's four of whom had experience, 15 were students, eight of whom had experience, and nine were unemployed, eight of whom were experienced.

\section{CONCLUSIONS}

Assessing the usefulness of available community groups for surveillance activities was the main driver for this exercise. However, it is clear from the study that selection of individuals based on their performance in test exercises is by far the best way to enhance the efficacy of surveillance for plant pest incursions. 


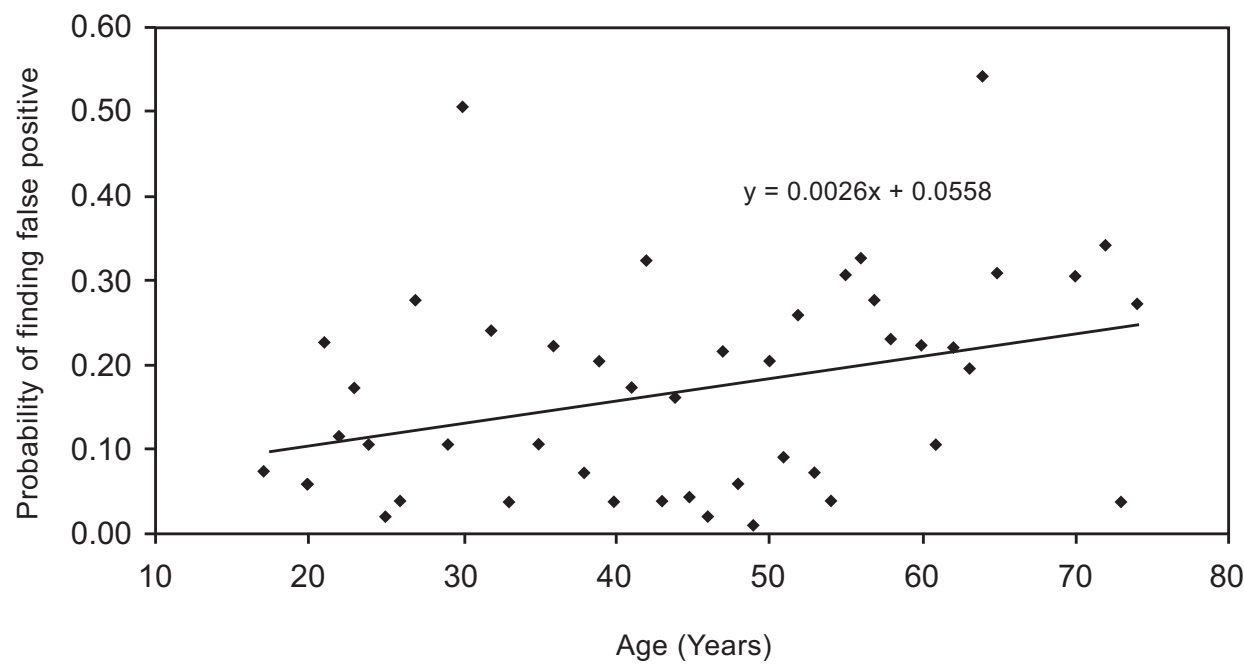

Fig. (7). Fitted linear relationship between age of participant and probability of finding false positive pest. Each point is the average for all participants of the same age after removing effects of experience.

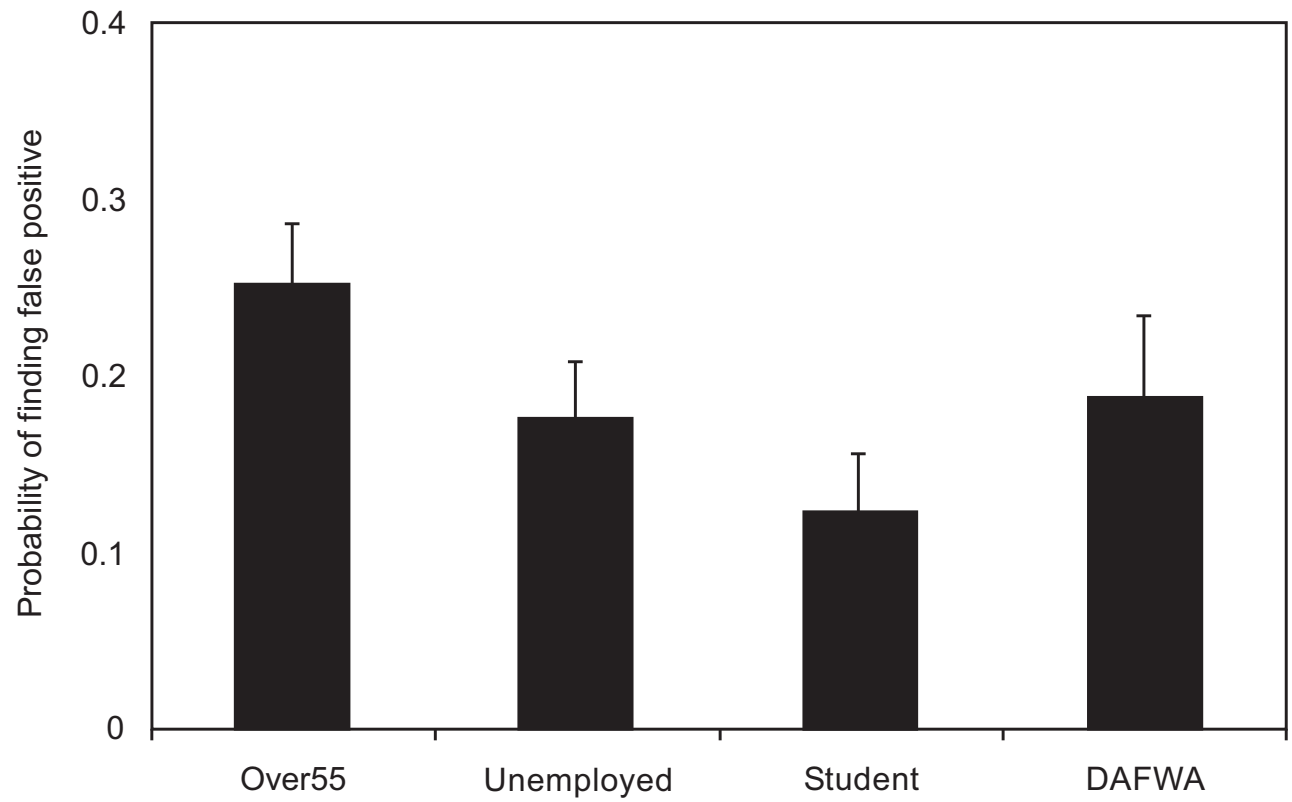

Fig. (8). Mean probability (+SE) of a false positive for each community and professional group.

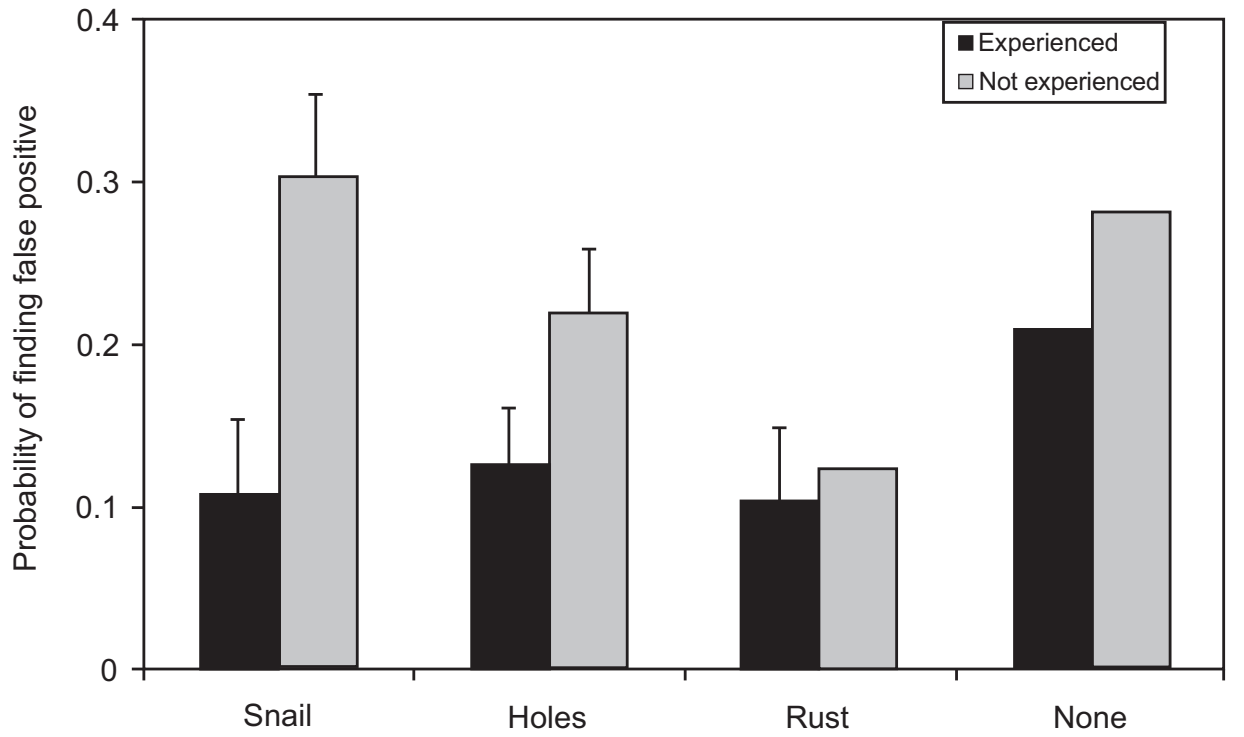

Fig. (9). Mean probability (+SE) of finding a false positive for each level of experience (after removing effects of age) for each pest. 
As expected, the type of fictitious target pest (size, appearance and level of concealment) had a large bearing on the resultant probability of finding the correct pest. The proportion of successful detections ranging from $21.5 \%$ (blue snails) to $59.4 \%$ (pink rust) and provides a valuable indicator level of potential success for actual field surveillance operations. Logically, it would seem that many more people would be required for surveillance of a small or potentially cryptic target pest than for a much larger or overt target. The overall number of targets detected by individual participants suggests that in the event of an actual incursion with similar pests, having similar densities and level of concealment, surveillance staff would on average be expected to find less than a third of the actual number of pests.

This exercise was valuable in providing an understanding of the importance of experience in planning and preparation before a surveillance event. Participants needed clear and concise briefing information on procedures, expectations and visual aids prior to commencing the exercise. Small details, such as providing a rest break between some zones and an opportunity to ask questions of marshals, were important in the overall performance and motivation of participants. These issues were addressed before the actual exercise, but could easily be glossed over or ignored in a real field incursion when less preparation time is available.

We want to reinforce the fact that, in the absence of other information; it would be desirable to choose young experienced staff to detect the presence of a pest. However, if there is information available regarding the competence of staff, then this is probably a better basis for selection. It would be useful to design some type of rapid competency assessment test which is able to be tailored to suit each surveillance programme.

This project is a first step in acquiring data pertaining to the capacity of community groups to carry out surveillance activities. This type of exercise needs to be repeated in a variety of communities with similar groupings. Similarly, it would be useful to undertake an exercise that compares personnel experience in surveillance for a specific target, with personnel who are experienced in biological pest surveillance but not familiar with the particular target pest, and with personnel without experience.

\section{ACKNOWLEDGEMENTS}

We thank the staff of the Department of Agriculture and Food, Western Australia for participation and support during the running of this surveillance exercise. Planning and practical assistance was provided by Rebecca Graham, Mark Pleysier, Bob McNeice, Vicki Mangano, Mike Grimm and Jane Ray. We also thank the co-operation by Keith Bodman and Sue Norelli at the Western Australian Horticulture and Environmental Science Skills Centre of Challenger TAFE and the support provided by Peter Stuart and Josh Byrne at the Environmental Technology Centre of Murdoch University, Perth, Western Australia, for use of facilities. Funding support was received from the Australian Government, Department of Agriculture, Fisheries \& Forestry and Plant Health Australia.

\section{ABBREVIATIONS}

DAFWA $=$ Department of Agriculture and Food Western Australia
IPPC $=$ International Plant Protection Convention

SPS = Sanitary and Phytosanitary

ISPM = International Standards for Phytosanitary Measures

TAFE $=$ Technical and Further Education

\section{REFERENCES}

[1] Australia Grains Industry Alliance (AGIA). Quarantine and Biosecurity Review. Federal Goverment's Biosecurity and Quarantine Review 2008.

[2] Pheloung P. Contingency planning for plant pest incursions in Australia. In: Identification of risks and management of invasive alien species using the IPPC framework. FAO. Proceedings of a workshop on invasive alien species and International Plant Protection Convention Braunschweig, Germany 2005; pp. 166-74.

[3] Hellström JS. Opening address: Biosecurity Surveillance. In: Froud KJ, Popay AI, Zydenbos SM, Eds., Surveillance for biosecurity: Pre-border to pest management. New Zealand Plant Protection Society (Incorporated), Hastings, New Zealand 2008; pp. 1-9.

[4] Steven P. Foreword. In: Froud KJ, Popay AI, Zydenbos SM, Eds. Surveillance for biosecurity: Pre-border to pest management. New Zealand Plant Protection Society (Incorporated), Hastings, New Zealand 2008.

[5] ISPM. No.04. Requirements for the Establishment of Pest Free Areas International Standards for Phytosanitary Measures. IPPC, FAO 1995

[6] Kean JM, Phillips CB, McNeil MR. Surveillance for early detection: lottery or investment? In: Froud KJ, Popay AI, Zydenbos SM, Eds. Surveillance for biosecurity: Pre-border to pest management. New Zealand Plant Protection Society (Incorporated), Hastings, New Zealand 2008; pp. 11-18.

[7] Kompas T, Bhu Che T, Van HAP. An optimal surveillance measure against Foot-and-Mouth disease in the United States, International and Development Economics. Crawford School of Economics and Government, The Australian National University, Canberra 2006; pp. 1-23.

[8] Campbell M, Gould B, Hewitt CL. Survey evaluations to assess marine bioinvasions. Marine Pollut Bull 2007; 55: 360-78.

[9] Born W, Rauschmayer F, Brauner I. Economic evaluation of biological invasions - a survey Ecological Economics 2005; 55: 321 36.

[10] NISC-National Invasive Species Council. General Guidelines for the Establishment and Evaluation of Invasive Species Early Detection and Rapid Response Systems. 2003; Version 1. 16.

[11] National Plant Health Status Report 08/09. Plant Health Australia, Canberra, ACT 2009.

[12] Beare S, Elliston L, Abdalla L, Davidson A. Improving plant biosecurity systems: A cost-benefit framework for assessing incursion management decisions. ABARE eReport 05.10. Prepared for Victorian Department of Primary Industries Canberra, October 2005.

[13] Bertram G. The impact of exotic pests on the New Zealand economy. In: Hackwell K, Bertram G, Eds. Pests \& weeds, a blueprint for action. Wellington, New Zealand: New Zealand Conservation Authority 1999; pp. 45-71.

[14] van Halteren P. Diagnostics and National Plant Protection Organizations. OEPP/EPPO Bull 2000; 30: 357-9.

[15] IPPC. New Revised Text approved by the FAO Conference at its 29th Session - November 1997, International Plant Protection Convention. FAO 1997.

[16] ISPM. No. 26. Establishment of pest free areas for fruit flies (Tephritidae). International Standards for Phytosanitary Measures IPPC, FAO 2006.

[17] Rodoni B. The role of plant biosecurity in preventing and controlling emerging plant virus diseases epidemics. Virus Res 2009; 141: 150-7.

[18] ISPM. No. 19. Guidelines on lists of regulated pests. International Standards for Phytosanitary Measures. IPPC, FAO 2003.

[19] Constable FE, Joyce PA, Rodoni BC. A survey of key Australian pome fruit growing districts for exotic and endemic pathogens. Aust Plant Pathol 2007; 36: 165-72.

[20] Froud KJ, Oliver TM, Bingham PC, Flynn AR, Rowswell NJ. Passive surveillance of new exotic pests and diseases in New Zea- 
land. In: Froud KJ, Popay AI, Zydenbos SM, Eds. Surveillance for biosecurity: pre-border to pest management. New Zealand Plant
Protection Society (Incorporated), Hastings, New Zealand 2008; pp. 97-110.

Received: December 10, 2009

Revised: October 07, 2010

Accepted: October 19, 2010

(c) Mangano et al.; Licensee Bentham Open.

This is an open access article licensed under the terms of the Creative Commons Attribution Non-Commercial License (http://creativecommons.org/licenses/by-nc/3.0/) which permits unrestricted, non-commercial use, distribution and reproduction in any medium, provided the work is properly cited. 